\title{
REVIEW STUDY ON PERFORMANCE OF SEISMICALLY TESTED REPAIRED SHEAR WALLS
}

\author{
S.KanakaDurga ${ }^{1}$, G. Appa Rao ${ }^{2}$ \\ ${ }^{1}$ Research Scholar, and ${ }^{2}$ Professor,Department of Civil Engineering, Indian Institute of Technology Madras, Chennai, India \\ Email: ${ }^{1}$ kanakadurga2004@gmail.com, ${ }^{2}$ garao@iitm.ac.in
}

\begin{abstract}
Shear walls are normally preferred in RC buildings and other important structures to resist the lateral forces due to earthquakes, wind storms, or impact loads. They are frequently encountered in earthquake resistant designs recently. This paper compiles the review of literature on structural behavior of RC shear walls under cyclic loading, before and after repair under similar loading condition. The performance characteristic such as strength, stiffness, energy dissipation, and modes of failure of squat shear walls repaired with different retrofitting techniques are presented.
\end{abstract}

\section{INTRODUCTION}

Shear walls are added to the structural system in order to provide lateral resistance against lateral loading due to wind or earthquake forces. Several improvements have been occurred over the past years in the design and detailing of $\mathrm{RC}$ walls. When the performance of the shear walls does not satisfy the requirements of strength, retrofitting techniques can be adopted to upgrade its performance level by any one of the methods practicable. "Rehabilitation" is the term used when the wall has already been damaged and its resistance needs to be restored and improved as well. "Strengthening" is the term used when the wall is not subjected to any damage.

The ratio of applied moment-to-applied shear force or aspect ratio $(\mathrm{A} / \mathrm{R})$ can be replaced with the ratio of wall height-tohorizontal wall length. The lateral loads can be resisted in shear walls either by cantilever action mostly in slender walls or high rise walls $(\mathrm{A} / \mathrm{R}>2)$ or by truss action in squat/short walls or low rise walls $(\mathrm{A} / \mathrm{R}<2)$. High-rise shear walls predominantly fail in flexure, whereas low-rise walls fail in shear. Squat shear walls are provided in important structures like nuclear plants where safety of the structure is a concern. Yielding of tension or compression steel or crushing of concrete at ultimate stages causes flexure cracks near the bottom part of the wall. Inadequate horizontal or diagonal reinforcement causes diagonal tension cracks. Sufficient shear reinforcement with formation of compression strut can lead to diagonal compression failure. Provision of sufficient horizontal reinforcement with inadequate vertical reinforcement can cause sliding shear.

Local buckling of web can be prevented by adding boundary elements such as columns or flanges at the wall ends, and minimum thickness of the web. Proper confinement of wall can prevent the in-plane splitting failure. Squat shear walls should be heavily reinforced to avoid shear-related failures. During an earthquake there may be a partial collapse (or damage) of the structure, which can be restored to original level. Many strengthening schemes such as use of FRP, FRC and steel jackets or steel cages, FRP reinforcing bars and pre-stressing strand are being adapted to bring the performance levels of the deteriorated structures for satisfying the performance requirements of the current design codes of practice. Most of the retrofit techniques have resulted in various levels of upgradation. However, issues like effectiveness, resources, invasiveness, cost and practical implementation are major challenges to be overcome. The present research paper focuses on strength retention of the original shear wall after repair and retrofitting with different techniques.

\section{Literature Review}

\subsection{Behaviour of Reinforced Concrete Shear Walls}

The behavior of shear walls has been reported by many researchers. The investigations on issues related to shear walls include; load-displacement response, crack pattern, modes of failure, variation of strains in reinforcement. The parameters normally studied from experimental investigations include shear strength, shear stress vs. shear strain response, story drift, energy dissipation, stiffness degradation, displacement ductility.

Oesterle et al. (1980) highlighted the importance of transverse reinforcement and also the anchorage of wall reinforcement into the boundary elements. The dimensions of hoop and spacing serve four primary functions: i) lateral confinement to increase limiting strain capacity of concrete core. ii) support vertical reinforcement in resisting inelastic buckling. iii) retain concrete within the core along with vertical bars iv) improves shear capacity and stiffness for dowel action of boundary elements. Four isolated RC walls with one-third scale factor were cast and tested under seismic loading. The wall with normal column tie spacing failed due to inelastic buckling of vertical reinforcement. The wall with special transverse reinforcement exhibited sufficient shear capacity for the formation of hinge at the 
base of boundary element. The anchorage of wall horizontal reinforcement plays an important role in the formation of horizontal cracks in the tension boundary element which subsequently propagated into web as diagonal crack. The horizontal web reinforcement need to be extended across the boundary element and terminated with standard $90^{\circ}$ bend for low shear walls and $135^{\circ}$ hook for high shear walls.

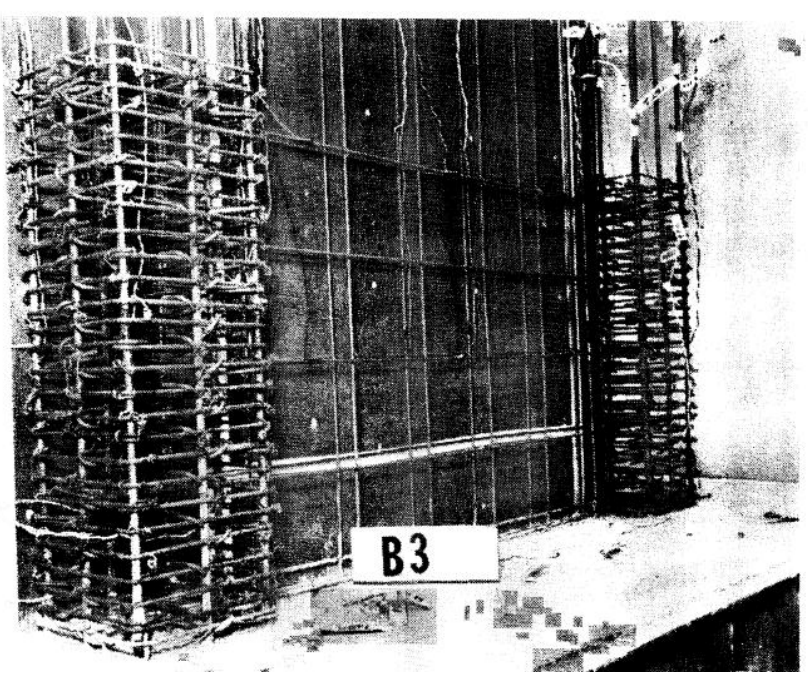

Ordinary column tie reinforcement

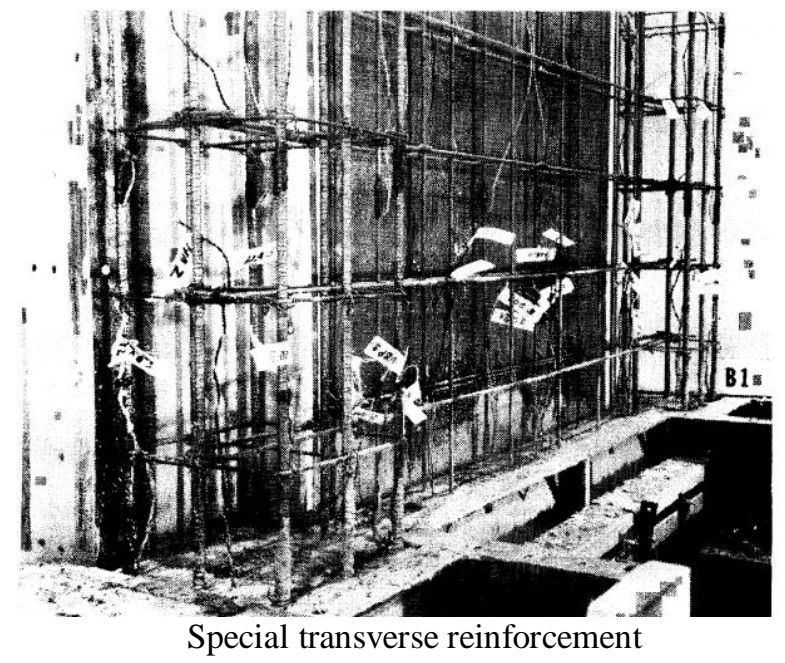

Fig. 1. Confinement reinforcement in boundary wall provided (Oesterle et al. 1980)

Salonikios et al. (1999) tested eleven reinforced concrete walls designed according to Eurocode 8 . The code provides different design equations for diagonal tension, diagonal compression and sliding shear modes of failure. The aspect ratios of the walls coincide with the shear ratio $a_{s}=M / V l_{w}$ since they are cantilever shear walls. Five walls have the aspect ratio of 1.0 and six with 1.5. The test parameters are aspect ratio, use of bidiagonal bars with and without distance at the intersection point at base, web reinforcement ratio, longitudinal reinforcement ratio, with and without axial loading, and presence of construction joints in one specimen with aspect ratio of 1.5. The walls were tested under three loading cycles at each ductility level. The walls failed predominantly in flexure mode, with intersection of flexural cracks originating from opposite edges. Concrete crushing and reinforcement buckling at the confined edges was observed. Pinching of hysteresis loop was observed in walls without diagonal bars due to horizontal sliding and bond-slip of vertical reinforcement. Sliding was controlled in walls with bidiagonal bars.
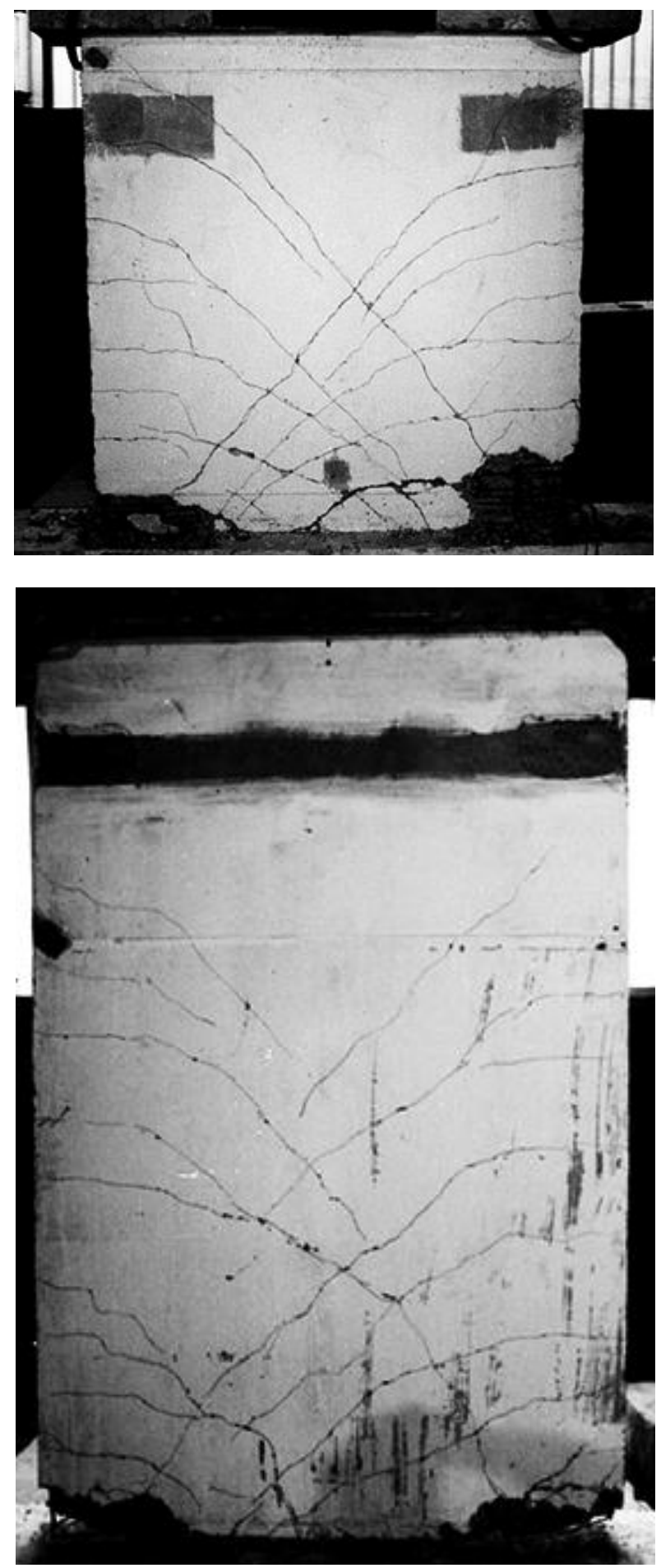

Aspect ratio 1.5

Fig.2.Failure pattern in RC wall with lateral and axial load (Salonikios et al. 1999). 
Salonikios et al. (2000) reviewed the strength characteristics of experimentally tested walls (1999) and focused on energy dissipation and stiffness degradation. A detailed discussion on Eurocode 8 and ACI 318 provisions for the design of shear wall is presented. The Eurocode considers the ductility in calculating the maximum capacity of walls. A reduction in the envelope curve is observed during second and third cycles of loading when compared to first cycle due to aggregate interlock and dowel action. Displacement ductility factor is the ratio of ultimate displacement (corresponding to a $25 \%$ drop in the peak strength) by yield displacement (corresponding to the development of $75 \%$ of the maximum strength). It is observed that at higher ductility total displacement is contributed by shear. All walls experienced stiffness degradation at higher levels of deformation. Specimens subjected to axial load in addition to lateral load and also with higher percentage of reinforcement in the web and boundary elements experienced low rate of degradation. Walls with aspect ratio 1.5 exhibited higher energy dissipation characteristics due to increased displacements. The provision of diagonal bars also contributed to higher energy dissipation capacity.

Palermo et al. (2002) provided experimental data on two full scale flange shear walls for constitutive models. The walls were tested under static and cyclic lateral displacements with and without axial load. The specimens had top slab serving the purpose of transferring loads to the wall and inturn it was anchored to the strong floor with bottom slab. Diagonal cracks extended over full height of the wall which increased in size with increasing displacements. Localized crushing was observed on the web wall due to non-realignment of cracks during unloading phase. Evenly spaced flexural cracks appeared throughout the height of the boundary element and vertical cracks appeared at the flange web connection. The wall without axial load had a sudden failure after peak load due to the formation of failure plane over the entire length of the wall. Concrete spalling at the toe of the web near the base slab was observed. Two second order phenomena namely flange elongation and bulging of the web wall were also studied. It has been concluded that squat shear walls produce highly pinched hysteresis response with little energy dissipation and influenced by shear mechanisms.

Hidalgo et al. (2002) experimentally tested twenty six full scale squat shear walls. The amount of vertical and horizontal reinforcement was varied for all the walls. The walls were tested without axial load, and horizontal cyclic load was applied at the mid-height of the walls. The walls without distribution reinforcement exhibited poor seismic characteristics after formation of the first major diagonal crack. The deformation capacity of the walls with low aspect ratio was decreased. Average normalized dissipated energy is calculated by summing up the energy dissipated in each individual cycle, and dividing the result by the number of cycles. It is observed that vertical distribution reinforcement had little or no influence on the maximum shear strength of the walls. There was increase in deterioration of strength as the aspect ratio of the walls decreased.

\subsection{Repair of Reinforced Concrete Shear Walls}

Galal et al. (2008) discussed the retrofitting methods of RC shear walls and emphasised that the retrofit technique should improve wall's seismic performance in terms of strength, stiffness, ductility or combination of all. The retrofit techniques using traditional methods are concrete replacement, concrete jacketing, steel sections, steel bracings, through-thickness rods and using new materials are FRP laminates and shape memory alloys. The factors that control the type of retrofitting technique for $\mathrm{RC}$ shear walls are: i) expected mode of failure ii) desired level of increase in stiffness, strength, ductility etc iii) budget for retrofit v) physical constraints such as architectural requirements, accessibility of the building during retrofitting process etc.

\subsubsection{Conventional repair technique}

Vecchio et al. (2002) tested repaired RC shear walls. The repair technique included recasting of web with new concrete up to top $180 \mathrm{~mm}$ from the soffit of the top slab and completed using a high-strength, non-shrink epoxy grout. Punching shear failure was observed in the web-flange joint, whereas shear slip failure at the base near the repair interface in the reconstructed walls.

\subsubsection{Externally bonded steel plates}

Elnashai et al. (1998) brought out selective techniques for repairing damaged walls. Use of external bonded steel plates was recommended for increasing the stiffness without altering the strength. The plates were bonded to the wall with epoxy mortars. The addition of external unbounded reinforcement bars increased the strength without affecting stiffness of the walls. Ductility can be increased by adding U-shaped external confinement steel plates. The shear strength can be enhanced by providing steel plates in horizontal bands. Strengthening of RC structural members with externally bonding steel strips is an effective technique for improving the seismic resistance. Considerable research has been performed on columns and beams, low masonry walls to increase the shear capacity of these members. Altin et al. (2013) extended this technique to $\mathrm{RC}$ walls subjected to earthquake loading. Four walls deficient in shear strength were cast; one controlled wall and three were strengthened with steel strips. A scale factor of 2 and a slenderness ratio (the ratio of length-to-width) of 1.5 was used. A head beam for transfer of lateral load and a foundation for anchoring the walls to the floor are cast integrally with the wall panel (shear wall). The wall was provided with $6 \mathrm{~mm}$ diameter horizontal and vertical reinforcement in two layers and a concentrated vertical reinforcement of $16 \mathrm{~mm}$ at end regions. Concrete of $18 \mathrm{MPa}$ compressive strength was used. The three walls vary in the alignment of steel strips such as diagonal, lateral and a combination of lateral and vertical. Steel strips were bonded to the walls after 28 days of curing and then walls were tested after 15 days. All the walls were 
subjected to lateral load. Application of epoxy adhesive to surface of the wall and insertion of anchor rods prevented debonding of steel strips and delayed premature buckling of steel strips.

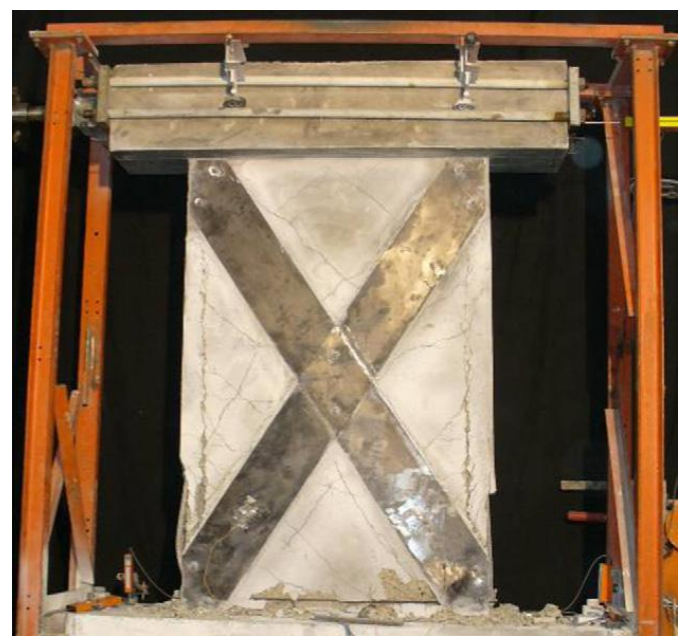

Control specimen

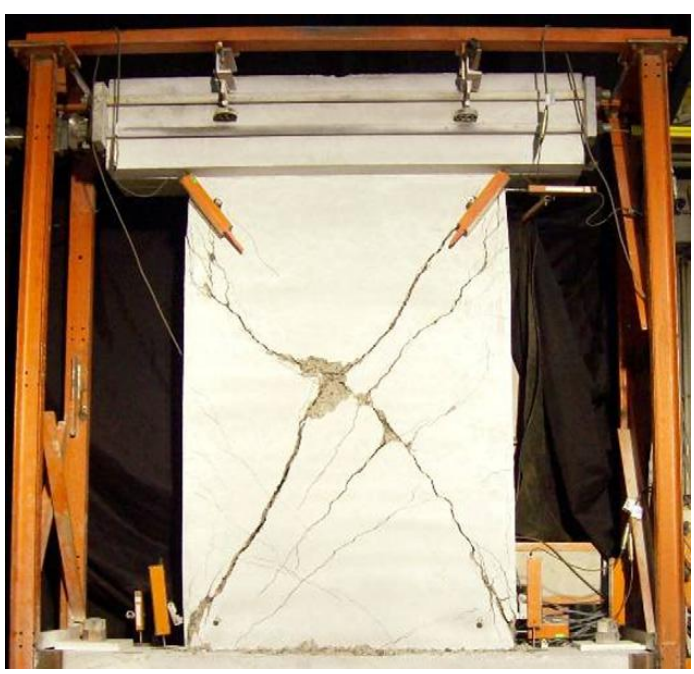

Diagonal steel strips

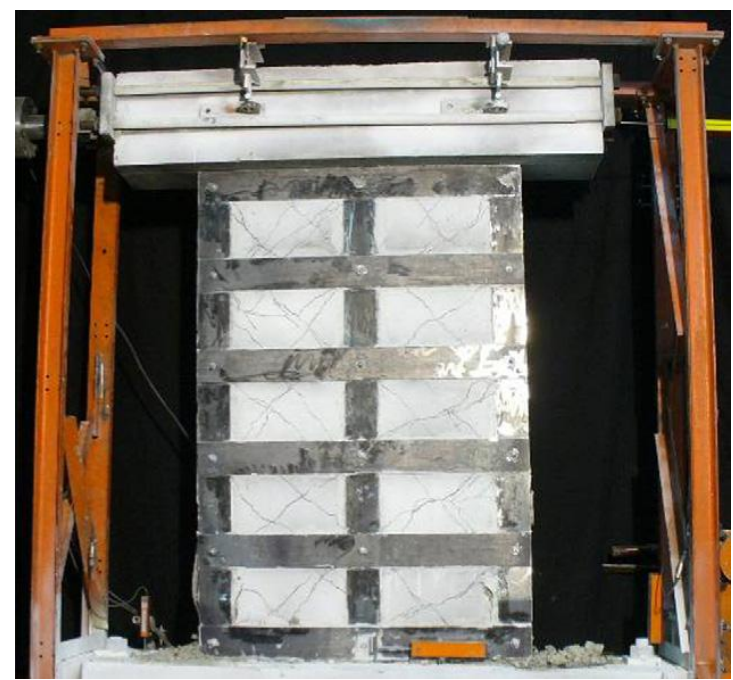

Lateral steel strips

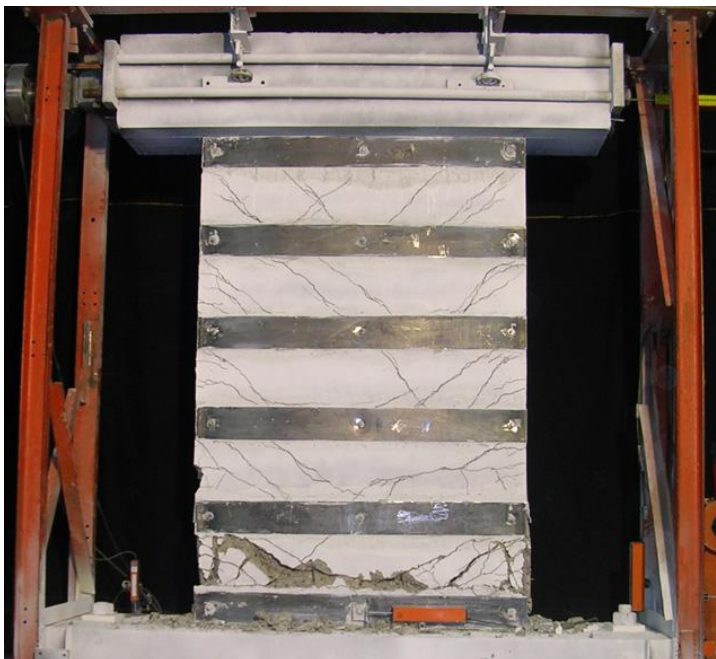

combination of lateral and vertical steel strips

Fig. 3.Control and strengthened specimens with steel strips (Altin et al. 2013)

The reference walls failed in diagonal tension shear. Such failure was prevented in strengthened walls due to shear strength of bonded steel strips. The maximum base shear was controlled by flexure. The anchors enabled in limiting the opening of shear cracks thereby increasing the lateral load, drift energy dissipation capacities of the strengthened walls. Shear sliding displacements were observed once the strengthened walls attained their flexural capacities. The strengthened walls exhibited $65 \%$ higher ultimate strength, improved initial stiffness and ductility than the controlled walls.

\subsubsection{Concrete jacketing}

Concrete jacketing is one of the measures to be used in seismic strengthening where new concrete is cast against an existing surface. The two materials vary in age and hence it is necessary to study the shear transfer capacity at the interface. Bass et al. (1989) tested thirty-three push off specimens to determine shear force at the interface. The specimen consists of column referred as "base block" and the infill wall constructed above the base block referred as "new wall". Specimens were cast in vertical, horizontal overhead positions. Different interface characteristics were adopted, which include; untreated, heavily sand blasted, chipped to achieve surface roughness, provided with shear key and coated with epoxy agent before pouring new concrete. It has been concluded that increase in embedment depth, amount of reinforcement, and use of deep surface preparation techniques at the interface results in high shear strength at higher slip levels. 


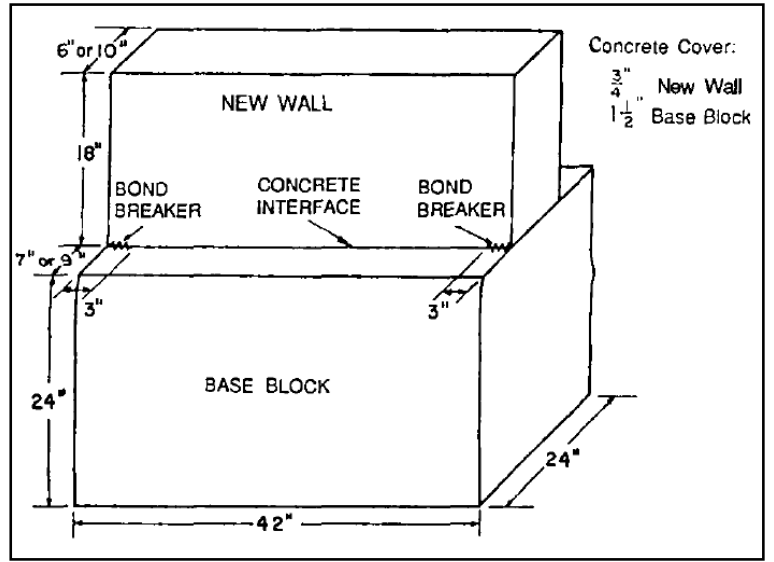

Fig. 4. Typical push-off specimen (Bass et al. 1989)

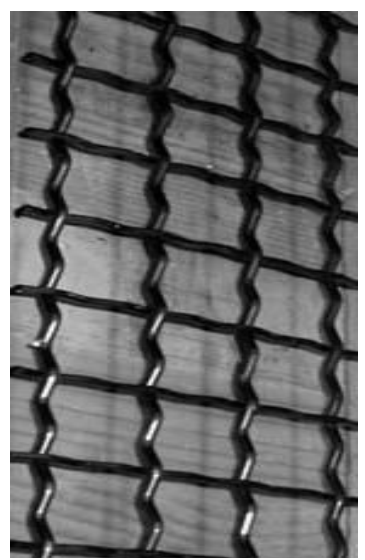

Fig. 5. High Strength steel mesh used in specimens (Marini et al. 2008)

Marini et al. (2008) assessed the effectiveness of seismic strengthening of RC shear walls with thin high performance jackets. One-third scaled shear walls were designed only for gravity load, strengthened with high performance jackets and tested under cyclic loading. High performance jacket includes a steel mesh with tensile strength of $1200 \mathrm{MPa}$ covered with a thin layer of concrete of compressive strength greater than $140 \mathrm{MPa}$. The steel mesh consisted of bent weaved wires of $2 \mathrm{~mm}$ diameter and $20 \mathrm{~mm}$ spacing. A uniform crack pattern with limited opening extended from the wall base to the critical zone of failure. The failure was governed by bending moment upto collapse. The failure of strengthening walls occurred due to crushing of concrete jacket at the base, exhibiting high ultimate strength, structure deformation capacity and ductility.

\subsubsection{Fibre reinforced polymers}

Lombard et al. (2000) studied the effectiveness of externally bonded carbon fibre tow sheets for seismic strengthening and repair of reinforced concrete walls. As a part of the experimental work, one controlled, a repaired and two strengthened walls were tested. The carbon fibre sheets were bonded to surface of the walls using epoxy matrix and anchored to the foundation. The damaged wall was repaired by one vertical layer of FRP. The undamaged walls are also strengthened with FRP. The failure in control wall was due to crushing of concrete at the toe of the wall. The repaired wall regained $90 \%$ of the initial stiffness and experienced ductile failure in flexure mode. The strengthened walls had increased secant stiffness and load carrying capacity.

Antoniades et al. (2003) retrofitted squat RC shear walls with FRP jackets in combination with FRP strips in order to increase the strength of heavily damaged during earthquake. The original walls were designed according to Eurocode 8 provisions. The spacing of web reinforcement and arrangement of bidiagional reinforcement were varied. One wall was repaired conventionally by replacing damaged concrete with non shrink mortar, and welding of fractured reinforcement. Remaining damaged walls were strengthened with FRP. Repaired wall could achieve original strength but showed less initial stiffness and energy dissipation capacity when compared to original wall. The hysteresis behaviour and initial stiffness of FRP strengthened wall was more than the conventionally repaired wall but less than that of the original wall. The propagation of existing shear cracks was prevented by FRP jackets.

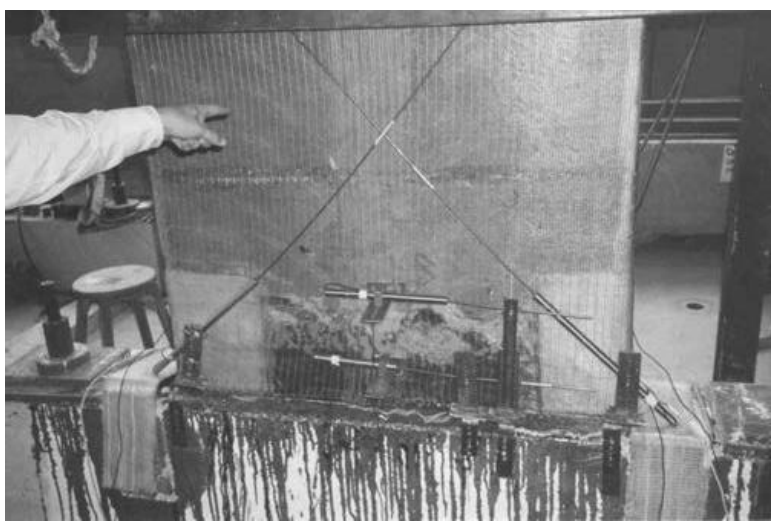

Fig. 6.Failure pattern in FRP strengthened wall (Antoniades et al. 2003)

Paterson et al. (2003) performed tests on strengthened RC shear walls with poor detailing. The detailing deficiencies include lap splicing of the longitudinal reinforcement in the plastic hinge region, poor confinement of boundary elements and anchorage of transverse reinforcement, and insufficient shear strength to develop hinging. The walls cantilevering from a heavily reinforced foundation block were anchored to the strong floor and tested in horizontal position. The first control specimen was provided with lap splice at the base and failed due to failure of lap splice. The lap splice was provided in the region of flexural hinging in the second control wall and it exhibited more ductile capacity than the first control wall. One wall was retrofittedwith provision of reinforced collar and wrapping it with carbon fibre to increase the shear strength. Another wall was retrofitted with additional confinement reinforcement over the lap splice region along with headed bars and CFRP wrapping. The retrofitted walls exhibited good displacement ductility, energy absorption and flexural hinging. The combination of headed reinforcement with CFRP reduced the shear distress and was effective in confining the boundary elements. 


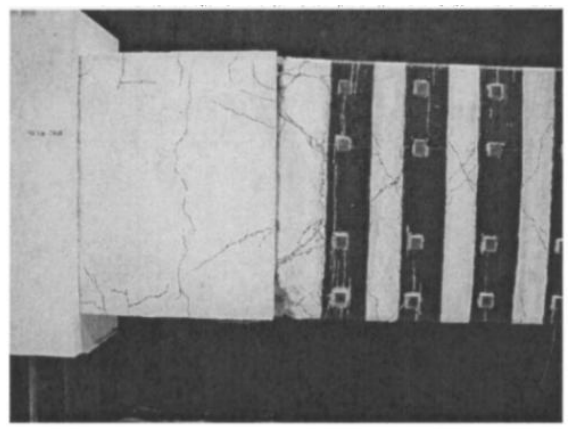

Wall with reinforced collar and CFRP

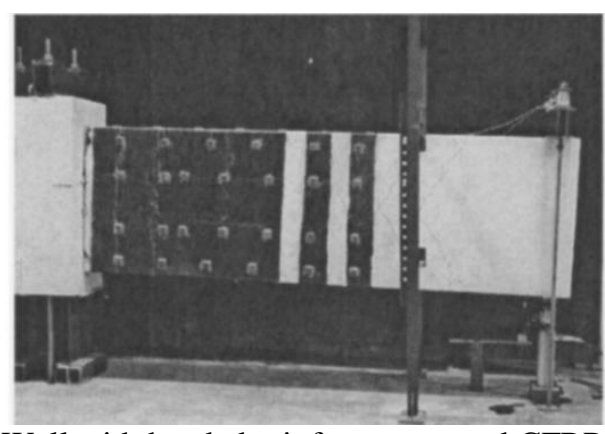

Wall with headed reinforcement and CFRP

Fig.7. Failure pattern in strengthened walls byPaterson et al. (2003)

Ghobarah et al. (2004) rehabilitated RC walls with fibre composites to enhance the wall capacity to earthquake loads and also ductility. Three walls were tested; control wall, upgraded with bi-directional fibre-reinforced sheets and bidirectional sheets anchored with additional steel bolts. The control wall was deficient in shear and ductility. The rehabilitated walls were wrapped with bi-directional sheets in the wall region and uni-directional sheets on the boundary elements. The boundary elements were also provided with FRP anchors in the upgraded walls. The control wall developed tension cracks at the bottom and midheight of the wall. Diagonal cracks were formed in both the directions increased in size leading to complete shear and sudden failure of the wall. Crushing of concrete was observed at the toe of the wall on the compression side and the vertical steel in the boundary elements buckled. The horizontal bars yielded and the tensile strains were recorded both in pushing and pulling direction. In the first rehabilitated wall delamination of CFRP sheets occurred at ductility level 1.5 in the wall region but they were intact in the boundary elements. FRP anchors failed at the bottom region of the wall and as a result concrete crushing and buckling of steel lead to failure of the specimen. In the second rehabilitated wall debonding of CFRP sheets was controlled by the steel anchors which resulted in less reduction in stiffness and more energy dissipation capacity. The rehabilitated walls recorded more strain in concrete, less strain in horizontal bars, higher displacement ductility than the control wall. The alignment of fibres at 45 degrees prevented shear mode of failure. FRP anchors failed in shear but steel anchors failed due to yielding. The confinement of the boundary elements with CFRP sheets delayed concrete crushing and also enabled in developing full tension in longitudinal bars.

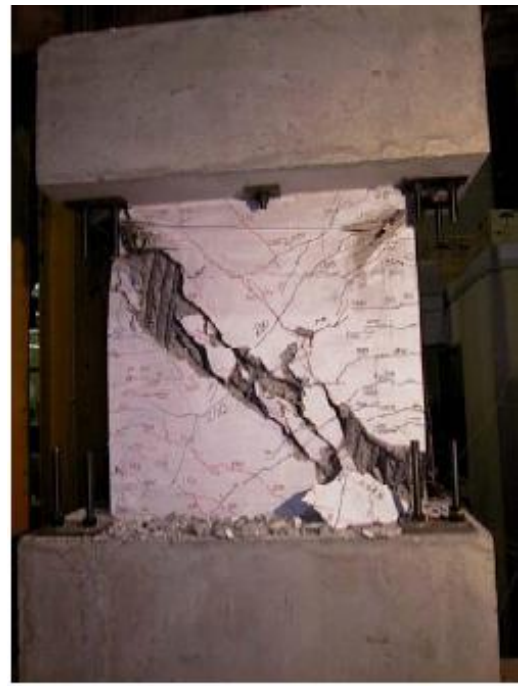

Control wall

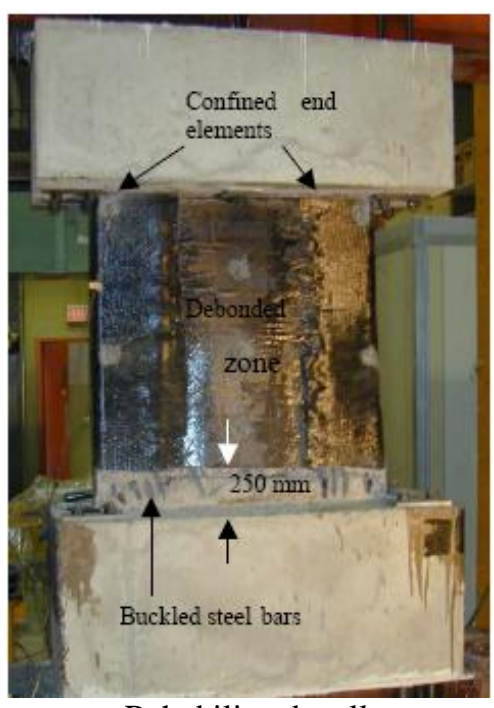

Rehabiliated wall

Fig. 8. Failure mode in walls (Ghobarah et al. 2004)

Li et al. (2010) designed eight walls with less confinement reinforcement as recommended by New Zealand Concrete Design Code and American Concrete Institute Code. The variables were: aspect ratio, axial load and the amount of distribution reinforcement in the wall. The walls had boundary elements and were categorized as low or medium rise as per the aspect ratio. Four original and four walls repaired and retrofitted with GFRP/ CFRP were tested. The original walls failed in flexural mode, exhibited heavy damage at the base with shear and flexural cracks along the height. The repair and retrofit methodology includes removal of damaged concrete and replacing with polymer modified repair mortar, injection of epoxy into cracks at the base of the wall and strengthening with FRP material. GFRP U-shaped jacket was used to confine the flange walls and GFRP anchors were provided along the development length of the sheets. The repaired walls showed less stiffness degradation, more ductility, and recovered almost original strength before post-peak than the original specimens. It has been observed that strength retention of CFRP wrapped specimens is more than GFRP specimens. 


\section{CONCLUSION}

Several repair and retrofit techniques adopted for improving the seismically deficient, undamaged and seismically damaged squat shear walls to validate experimentally has been reviewed. The conventional technique of removing and replacing damaged material retains the original strength but exhibits less energy dissipation capacity and initial stiffness. The stiffness, strength and ductility of undamaged walls can also be improved by using steel plates. Concrete jacketing is an effective retrofit technique and can be adopted in practice. Fibre-reinforcement polymers application in strengthening of undamaged and damaged shear walls has increased due to ease of application. The problem of delamination of fibres occurs in FRP strengthened walls only after attaining the peak load. The retrofitted walls exhibited flexure mode of failure, improved energy dissipation, and less stiffness degradation.

\section{REFERENCES}

1. Oesterle, A.E., Fiorato, A.E., and Corley, W.G. (1980). Reinforcement Details for Earthquake-Resistant Structural Walls. Concrete International, Dec., 55-66.

2. Salonikios, N. Thomas., Kappos, J. Andreas., Tegos, A. Ioannis., and Penelis, G. Georgios. (1999). Cyclic Load Behavior of Low-Slenderness Reinforced Concrete Walls: Design Basis and Test Results. ACI Structural Journal, 96(4), 649-661.

3. Salonikios, N. Thomas., Kappos, J. Andreas., Tegos, A. Ioannis., and Penelis, G. Georgios. (2000). Cyclic Load Behavior of Low-Slenderness RC Walls: Failure Modes, Strength and Deformation Analysis, and Design Implications. ACI Str Jl, 97(1), 132-142.

4. Palermo, D., and Vecchio, F.J. (2002). Behavior of Three-Dimensional Reinforced Concrete Shear Walls. ACI Stl Jl, 99(1), 81-89.

5. Hidalgo, P.A., Ledezma, C.A., and Jordan, R.M. (2002). Seismic Behaviour of Squat Reinforced Concrete Shear Walls. Earthquake Spectra, 18(2), 287308.

6. Galal, K., and EI-Sokkary, H. (2008). Recent Advancements in Retrofit of RC Shear Walls. $14^{\text {th }}$ World Conference on Earthquake Engineering. October 12-17, 2008.

7. Frank, J. Vecchio., Omar, A. Haro de la Pena., Filippo Bucci., and Daniel Palermo (2002). Behaviour of Repaired Cyclically Loaded Shear Walls. ACI Str Jl, 99(3), 327-334.

8. Elnashai, A.S., and Pinho, R. (1998). Repair and Retrofitting of RC Walls Using Selective Techniques. Journal of Earthquake Engineering, 2(4), 525-568.

9. Altin, S., Kopraman, Y., Baran, M. (2013). Strengthening of RC walls using externally bonding of steel strips. Engineering Structures, 49, 686-695.

10. Bass, A. Robert., Carrasquillo, L. Ramon., and Jirsa, O. James. (1989). Shear Transfer across New and Existing Concrete Interfaces. ACI Str Jl, 86(4), 383-393.

11. Marini, A., and Meda, A. (2008). Seismic Retrofitting of Existing Shear Walls by means of High Performance
RC Jacket. $14^{\text {th }}$ World Conference on Eq Engg. October 12-17, 2008.

12. Lombard, J., Lau, David. T., Humar, Jag. L., Foo, S., and Cheung, M.S. (2000). Seismic Strengthening and repair of RC Shear walls. $12^{\text {th }}$ World Conference on EQ Engg. 2000.

13. Antoniades, K. Konstantinos., Salonikios, N. Thomas., and Kappos, J. Andreas. (2003). Cyclic Tests on Seismically Damaged Reinforced Concrete Walls Strengthened Using Fiber-Reinforced Polymer Reinforcement, ACI Str Jl,100(4), 510-518.

14. Paterson, J., and Mitchell, D. (2003). Seismic retrofit of shear walls with headed bars and carbon fiber wrap. ASCE Journal of Structural Engineering, 129(5), 606614.

15. Ghobarah, A., and Khalil, A.A. (2004). Seismic Rehabilitation of Reinforced Concrete Walls Using Fibre Composites. 13 ${ }^{\text {th }}$ World Conference on EQ Engg. August 1-6, 2004.

16. Li, B., and Lim, C.L. (2010). Tests on Seismically Damaged RC Structural Walls Repaired Using FibreReinforced Polymers. Journal of Composites for Construction, 14(5), 597-608. 